\title{
A Wikipédia como fonte de informação de referência: avaliação e perspectivas
}

\author{
Wikipedia as reference source: assessment and prospects
}

\author{
[Preprint de artigo submetido em 20/07/2017 a Perspectivas em Ciência da Informação] \\ Vinícius Medina Kern ${ }^{1}$ \\ Universidade Federal de Santa Catarina
}

\begin{abstract}
Resumo
A Wikipédia é citada em revistas científicas de alto impacto, apesar de sua má reputação como fonte de informação. O que sustenta essa aceitação? Em busca de respostas, este artigo apresenta uma avaliação da Wikipédia anglófona segundo o roteiro de Silberger para obras de referência quanto ao propósito, alcance, arranjo, informação dada, acesso e características especiais, com um aspecto adicional: o controle da qualidade do conteúdo. Complementa essa avaliação um relato da experiência do autor na criação de um verbete em português. Em conclusão, a Wikipédia tem conteúdo de alta qualidade, com vantagens como o grande volume de conteúdo em muitas línguas, bem como desvantagens, como a ênfase em tópicos "populares". Há também conteúdo inadequado, cuja contenção e reparo dependem da capacidade e engajamento da comunidade linguística que a edita, bem como do respeito a seus princípios editoriais. Há oportunidade para engajar estudantes do ensino superior na criação de conteúdos, bem como na avaliação, que é uma forma de "revisão por pares". O bom uso da Wikipédia depende essencialmente da capacidade crítica do leitor.
\end{abstract}

Palavras-chave: Wikipédia; Enciclopédias; Obras de referência; Curadoria digital; Revisão pelos pares.

\begin{abstract}
Wikipedia is cited in high-profile scientific journals, despite its poor reputation as information source. What warrants this acceptance by scientists? In search for answers, this article presents an assessment of the English Wikipedia according to Silberger's guide for reference works, analyzing its purpose, scope, arrangement, information given, access, and special characteristics, with an additional aspect: quality control of new content. An account of the author's experience in creating an entry in the Portuguese Wikipedia complements the assessment. In conclusion, Wikipedia has high quality content, with advantages such as the large volume of content in many languages, as well as disadvantages such as the emphasis on "popular" topics. There is also inadequate content, whose containment and repair depend on the literacy and engagement of the linguistic community that publishes it, as well as on following Wikipedia's editorial principles. Content creation is an opportunity to engage higher education students, as well as content evaluation, which is a form of peer review. Fruitful use of Wikipedia content depends essentially on the reader's critical judgment.
\end{abstract}

Keywords: Wikipedia; Encyclopedias; Reference materials; Digital curation; Peer review.

1 Universidade Federal de Santa Catarina, Departamento de Ciência da Informação, CED Bloco C, sala 207, 88010-970 - Florianópolis, SC - Brasil, www.kern.prof.ufsc.br.

Bolsista de produtividade em pesquisa do CNPq, PQ-2, área Comunicação e Informação 


\section{Introdução}

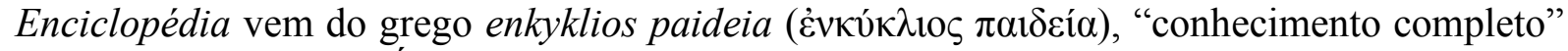
ou "educação geral". É um tipo de obra de referência organizada por artigos ou verbetes, usualmente em ordem alfabética. A enciclopédia mais antiga existente é a Naturalis Historia (circa 77 D. C.) de Plínio O Velho. As modernas evoluíram a partir de dicionários, no Século XVI (ENCYCLOPEDIA, 2016).

A Wikipédia, enciclopédia colaborativa multilíngue online (https://www.wikipedia.org), frequentemente é vista no meio acadêmico como fonte de informação inadequada. Demo (2010) aponta seu ambiente conturbado por "guerras de edição", nas quais contribuidores lutam para manter seu texto enquanto suprimem o de outrem, embora admita haver grande interesse e originalidade na obra.

As avaliações de qualidade da Wikipédia tiveram grande impacto a partir de um estudo publicado na revista Nature (GILES, 2005), concluindo haver qualidade semelhante entre artigos selecionados da Wikipédia, quatro anos após seu lançamento, e da Encyclopedia Britannica, existente há quase dois séculos e meio. A Britannica (2006) refutou, sob o título "Fatalmente falho".

Essa polêmica foi seguida por muitas outras avaliações e estudos comparativos. Hjørland (2011) propôs um método e alguns critérios para avaliar fontes de informação, com os quais analisou quatro enciclopédias quanto à qualidade como fonte de informação para um tema específico e controverso: o efeito dos exames de detecção precoce de câncer de mama. Concluiu que a melhor das quatro foi a Wikipédia em inglês, seguida da Enciclopédia Nacional Dinamarquesa, da Encyclopedia Britannica e da Wikipédia em dinamarquês.

Mesgari et al. (2015) revisaram sistematicamente 110 artigos sobre o conteúdo da Wikipédia. Identificaram duas correntes principais de pesquisa: sobre a qualidade do conteúdo (incluindo abrangência, atualidade, legibilidade e confiabilidade) e sobre seu tamanho. Encontraram estudos que reivindicam a superioridade e outros que atestam a inferioridade da Wikipédia em relação a outras fontes bem estabelecidas. Exceto na área da Saúde, em que alguns estudos reprovam a qualidade da Wikipédia, seu conteúdo é geralmente considerado confiável.

Stvilia et al. (2008) analisaram a organização do trabalho de garantia de qualidade da informação na Wikipédia. Apontam seus processos de trabalho (workflow) que permitem acionar mecanismos de qualidade da informação por meio de tecnologia relativamente simples. Na Wikipédia, todas as versões de um verbete e as discussões relacionadas estão disponíveis, facilitando as pesquisas sobre esse trabalho colaborativo e, muitas vezes, conflitivo.

Em resumo, a literatura internacional parece convergir para o que concluem Arazy et al. (2011): que o sucesso da Wikipédia mostra que é possível comunidades auto-organizadas construírem produtos informacionais de alta qualidade. As análises da Wikipédia são cada vez mais detalhadas e críticas, sem espaço para elogios ou rejeições simplistas.

A literatura brasileira em ciência da informação está em acordo com os estudos internacionais. D’Andrea (2009) comparou as políticas editoriais da Wikipédia e da Britannica Online. Encontrou semelhanças, porém há a diferença fundamental da ênfase na valorização da especialização, da Britannica, enquanto a Wikipédia enfatiza o engajamento dos usuários.

Ribeiro e Gottschalg-Duque (2012) compararam a qualidade de catorze verbetes sobre Biblioteconomia em inglês na Wikipédia e na Enciclopédia Britânica. Encontraram pequena diferença na qualidade informacional dos verbetes, com pequena vantagem para a Wikipédia, embora esta apresentasse maiores índices de imprecisão ou incorreção.

Gonçalves e Lima (2014) discutiram o processo de validação da informação na Wikipédia. Consideram que a informação é validada numa dinâmica em que prevalece a autoridade do argumento, em contraste com o argumento da autoridade. 
Sousa e Marques (2015) estudaram as edições dos verbetes referentes aos candidatos à prefeitura de São Paulo em 2012. Tratando-se de um processo eivado de conflitos de interesse, a dinâmica de edições dos verbetes foi afetada pelo acirramento da disputa eleitoral.

Apesar do que dizem essas pesquisas, a rejeição acadêmica à Wikipédia é comum. Jemielniak e Aibar (2016), analisando a literatura sobre seu uso acadêmico, afirmam que muito do descrédito vem da ideia preconcebida de que não é possível produzir colaborativamente uma enciclopédia de boa qualidade. Notam, no entanto, que os detalhes de seu sistema editorial são frequentemente desconhecidos ou mal compreendidos.

Seja preconceito ou reprovação embasada, essa má reputação não impede que a Wikipédia seja citada cada vez mais em fóruns científicos de alto impacto, altamente exigentes. A Wikipédia é fonte de informação de referência em artigos científicos, tanto em geral $^{2}$ quanto em bases de dados consideradas "de elite" como Web of Science (WoS) e Scopus, como se constata na Figura 1, apesar de variações nos resultados desses dois estudos.

Figura 1 - Citações às enciclopédias Britannica e Wikipédia em bases de dados
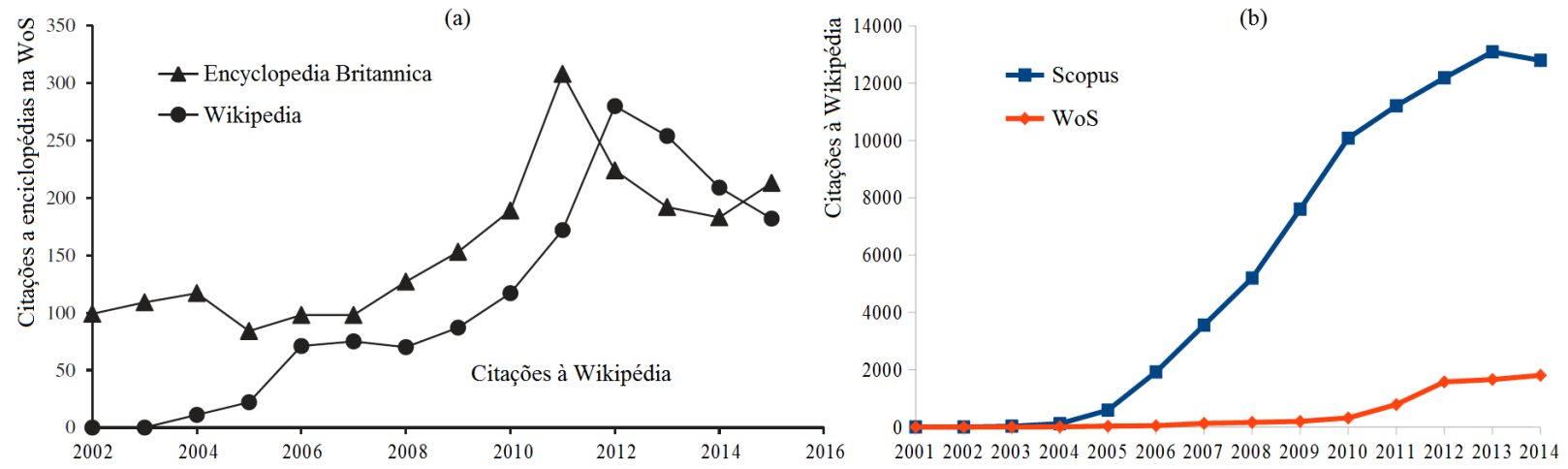

Fonte: (a) Tomaszewski \& MacDonald (2016) e (b) elaborado pelo autor a partir de Mahesh (2017)

O que sustenta a aceitação da Wikipédia como fonte nesses fóruns de alto nível, ao mesmo tempo em que há uma rejeição prima facie por muitos acadêmicos? Para buscar um entendimento crítico das razões para aceitar ou rejeitar o uso de conteúdo da Wikipédia, este artigo apresenta uma avaliação baseada no roteiro de Silberger (1990) para obras de referência. A avaliação é complementada por um relato da experiência do autor como wikipedista, i.e., autor-editor de verbetes.

Nas próximas seções, discutem-se a origem e evolução da Wikipédia e são apresentados os procedimentos metodológicos para a avaliação. Os resultados dessa avaliação são detalhados e discutidos, bem como ilustrados no caso da experiência do autor como wikipedista. As principais conclusões são: o processo de validação da informação pode falhar, mas parte de critérios mais científicos, menos baseado em autoridade, que nas enciclopédias tradicionais; a qualidade do conteúdo da Wikipédia parece depender do discernimento e engajamento da comunidade que a edita e de seu característico fluxo de trabalho (workflow) editorial, que permite a qualquer um editar verbetes, inclusive anonimamente, mas submete a aprovação dos conteúdos a uma revisão aberta, com hierarquia de editores. $\mathrm{O}$ processo editorial pode apresentar rigor e objetividade semelhantes a processos editoriais acadêmicos. Usar adequadamente a Wikipédia requer capacidade crítica do leitor.

2 Ver "Growth of academic interest in Wikipedia" em "Wikipedia:Academic studies of Wikipedia", https://en.wikipedia.org/wiki/Wikipedia:Academic_studies_of_Wikipedia\#Over_time, acesso em $28 \mathrm{dez}$. 2016. 


\section{Wikipédia: origem e evolução}

A própria Wikipédia conta sua história (WIKIPEDIA, 2017). É uma enciclopédia online gratuita que se propõe editável por qualquer pessoa com uma conexão à internet. Pertence à Wikimedia Foundation, mas tem acesso e edição livres. Com 5,3 milhões de verbetes, a versão em inglês (https://en.wikipedia.org/) é a maior dentre quase 300 wikipédias. No total, são cerca de 40 milhões de verbetes e 500 milhões de visitantes únicos por mês.

Foi lançada em 15 de janeiro de 2001 por Jimmy Wales e Larry Sanger, que a nomeou a partir dos termos "wiki" (termo havaiano para "rápido") e "enciclopédia". Começou pequena, mas em poucos anos chamou a atenção da mídia, qualificada como "experimento social fascinante"s.

Alguns detalhes da difícil história inicial escapam às páginas da Wikipédia, mas Shirky (2008) contribui para preencher essa lacuna. Wales obteve financiamento e contratou Sanger para supervisionar o desenvolvimento de uma enciclopédia gratuita e online, a Nupedia, a ser elaborada, revisada e gerida por peritos voluntários. A Nupedia foi lançada em março de 2000, mas não avançou na velocidade esperada. Sanger, então doutorando em filosofia, sugeriu a Wales criar rascunhos dos verbetes da Nupedia usando uma ferramenta chamada wiki, criada por Ward Cunningham em 1995.

Ainda segundo Shirky (2008), grande parte do esforço inicial da Nupedia foi empregado na formação de um conselho consultivo voluntário e na criação de diretrizes de política editorial e um processo (workflow) para criar, revisar e publicar verbetes e suas atualizações. $\mathrm{O}$ objetivo era assegurar altos níveis de qualidade, mas isso causou lentidão no avanço da Nupedia, com sete etapas editoriais, cada uma sujeita a causar atrasos.

A sugestão de Sanger, de criar rascunhos em wiki, baseava-se em um pressuposto inovador do criador Cunningham - de que grupos de pessoas que desejam cooperar também tendem à confiança recíproca, dispensando a burocracia controladora. A experiência de criar verbetes em wiki levou a um resultado esperado, a desburocratização das versões iniciais de verbetes, e a um inesperado, a oposição imediata e feroz de seu conselho consultivo.

Para Shirky (2008, p. 212), "[o] conselho tinha sido recrutado para supervisionar um processo rigoroso, projetado e dirigido por especialistas, e o wiki ofendeu seu entendimento da missão". Assim, para aplacar a ira do conselho, Wales e Sanger moveram o wiki para fora do sítio da Nupedia. Escolheram o endereço Wikipedia.com, dando origem à Wikipédia, que em poucas semanas ultrapassou o número de artigos da Nupedia, resultando que "a Wikipédia era viável, e a Nupédia, não" (p. 113).

Wales demitiu Sanger no final de 2001. Shirky (2008) afirma que a decisão se impôs porque a Wikipédia não gerava nem requeria receita, mas também porque Sanger enfureceu outros participantes do projeto ao declarar, em lista de discussão, que reservava-se o direito de excluir conteúdos pouco meritórios ou postados por pessoas que queriam solapar sua autoridade. A Wikipédia continuou crescendo sem Sanger. Atualmente, é o quinto sítio mais acessado da Web (http://www.alexa.com/topsites, 31 dez. 2016), atrás de Google.com, Youtube.com, Facebook.com e Baidu.com (motor de busca dominante na China).

No Brasil, como no resto do mundo, a Wikipédia encontra alguma aceitação acadêmica, mas predomina a rejeição. Foi tema, como ilustra a Figura 2, de uma questão do Exame Nacional de Desempenho de Estudantes (Enade), na prova aplicada aos graduandos em Biblioteconomia em 2006. Essa ocorrência num exame nacional de alto nível de qualidade, embora não indique aceitação ampla, mostra que há disposição no meio acadêmico para analisá-la criticamente.

3 Spreading Knowledge, The Wiki Way (artigo jornalístico de Leslie Walker para o Washington Post em 9 de setembro de 2004). Disponível em http://www.washingtonpost.com/wp-dyn/articles/A5430-2004Sep8.html. 
Figura 2 - Questão sobre a Wikipédia no Enade de Biblioteconomia, edição 2006

QUESTÃO 39 - Discursiva

A Wikipédia é uma enciclopédia livre escrita em colaboração pelos seus leitores. Livre aqui significa que qualquer artigo da Wikipédia pode ser copiado e modificado desde que os direitos de cópia e modificação sejam preservados. (...) A Wikipédia em língua portuguesa começou em 2002, a partir da tradução do conteúdo da versão original, em inglês, e cresceu com a produção de novos verbetes. A comunidade vem aumentando de dia para dia. Porém precisamos de mais colaboradores para poder ampliar o número de artigos em língua portuguesa e expandir, melhorar e consolidar os que já existem. (Internet: <pt.wikipedia.org/wiki/Wikipedia>, com adaptações.)

Considerando que o texto acima tem caráter unicamente motivador, redija um texto dissertativo de no máximo 10 linhas que ressalte dois aspectos positivos e dois aspectos negativos da Wikipédia como fonte de informação.

Fonte: Instituto Nacional de Estudos e Pesquisas Educacionais Anísio Teixeira (INEP), conforme registro em https://pt.wikipedia.org/wiki/Wikip \%C3\%A9dia:Esplanada/Arquivo/2006/Novembro\#Wikip.C3.A9dia no_ENADE.

\section{Procedimentos metodológicos}

A avaliação segue o roteiro de Silberger (1990) para enciclopédias, sumariado na Figura 3. Esse roteiro é parte de um livro que oferece critérios genéricos para avaliar obras de referência, bem como roteiros específicos por tipo de obra: dicionários, tesauros, bibliografias, catálogos coletivos, guias ou manuais bibliográficos, índices, concordâncias, enciclopédias, compêndios/manuais, fontes estatísticas, atlas e guias.

O roteiro de avaliação de enciclopédias de Silberger (1990) é anterior à Wikipédia, quando o modelo de negócio tipicamente sustentava-se na reputação de uma editora e na venda da obra em papel, usualmente encadernada em capa dura, em muitos volumes. Dessa forma, a avaliação que segue requer dispensar as obsolescências e levar em conta na análise o modelo de negócio da produção colaborativa voluntária online, examinando o mecanismo de controle da qualidade do conteúdo.

A avaliação da Wikipédia, apresentada a seguir em forma discursiva, é complementada por um relato da primeira experiência deste autor como wikipedista, autor de um verbete. $\mathrm{O}$ relato tem o intuito de exemplificar o funcionamento do processo editorial e é facilitado pela disponibilidade da versão original do verbete e de todos os estágios de discussão e versões parciais, o que é uma característica da Wikipédia para todos os seus verbetes, em todas as línguas disponíveis.

\section{Resultados: avaliação da Wikipédia e relato de experiência}

Os resultados incluem os seguintes aspectos previstos no roteiro de Silberger (1990) para avaliar enciclopédias: propósito, alcance, arranjo, informação dada, acesso e características especiais. A Wikipédia não tem as "páginas iniciais" que são usualmente fontes de informação essenciais para a avaliação, já que se trata de uma enciclopédia online em hipertexto. As principais fontes, que se assemelham em função às páginas iniciais de uma enciclopédia em papel, são citadas ao longo desta exposição de resultados. 
Figura 3 - Critérios para avaliar uma enciclopédia

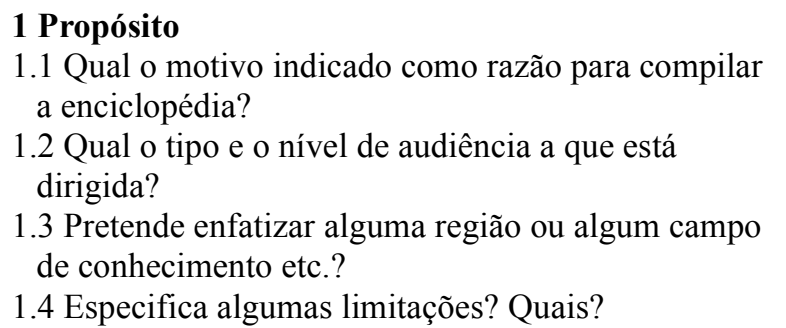

1.3 Pretende enfatizar alguma região ou algum campo de conhecimento etc.?

1.4 Especifica algumas limitações? Quais?

\section{Alcance}

2.1 Tipos de informações.

2.1.1 Geográficas.

2.1.1 Biográficas.

2.1.1 Políticas.

2.1.1 Científicas.

2.1.1 Históricas.

2.1.1 Culturais.

2.1.7 Outros

2.2 Os verbetes são extensos, discursivos e abrangentes, ou curtos e específicos?

2.2.1 Número de palavras em média por verbete.

2.2.2 Número de páginas em média por verbete.

2.2.3 Número de verbetes em total (pode estimar).

\section{Arranjo}

3.1 Alfabético por entrada.

3.2 Classificado.

3.2.1 Geográfico.

3.2.2 Assunto:

3.2.2.1 por divisões ou capítulos;

3.2.2.2 por verbetes específicos.

3.3 Outro.

\section{Informação dada}

4.1 Conceitos básicos gerais.

4.2 Definições.

4.3 Orientações históricas.
4.4 Dados biográficos.

4.5 Dados estatísticos.

4.6 Ilustrações:

4.6.1 retratos;

4.6.2 fotografias;

4.6.3 diagramas;

4.6.4 gráficos;

4.6.5 mapas.

4.7 Bibliografia.

4.7.1 Cita fontes de informação consultada?

4.7.2 Recomenda leitura adicional?

4.7.3 Inclui referências só na língua da enciclopédia ou apresenta referências em vários idiomas estrangeiros?

4.8 Verbetes assinados pelos autores.

\section{Acesso}

5.1 Remissivas.

5.1.1 ver, veja, vide etc.;

5.1.2 ver também, veja também etc;

5.1.3 explicativa.

5.2 Sumário

5.3 Índice.

5.3.1 Remete para as entradas?

5.3.2 Remete para informações específicas no corpo da obra?

5.4 Outro.

6 Atualização (obsoleto para avaliar fonte "viva"*)

6.1 Livro do ano

6.2 Outra forma de suplementação.

7 Equivalente automatizado (obsoleto*)

8 Características especiais

8.1 Traz dicionário em volume separado?

8.2 Traz atlas em volume separado?

Fonte: Silberger (1990, p. 116-118), com notas* do autor nos itens 6 e 7.

Existem quase três centenas de wikipédias (ABOUT, 2017), cada uma em uma língua ou subconjunto. Esta avaliação privilegia a versão anglófona (https://en.wikipedia.org), mais antiga e maior wikipédia em número de verbetes, com menções à Wikipédia lusófona (https://pt.wikipedia.org) no relato anedótico que sucede a avaliação.

Quanto ao propósito, embora não haja uma "declaração de propósito" formal e explícita, o cofundador da Wikipédia Jimmy Wales a descreveu como "um esforço para criar e distribuir uma enciclopédia multilíngue gratuita da mais alta qualidade para toda pessoa no planeta, em sua própria língua" (WIKIPEDIA, 2017). A Wikipédia existe para trazer conhecimento a todos que o buscam (OVERVIEW, 2017).

Por outro lado, a Wikipédia não é (WHAT, 2017): enciclopédia em papel, dicionário, fonte de conhecimento original, meio de se promover, repositório de links ou imagens ou arquivos multimídia, blog, home page, rede social, lista ou diretório, manual ou guia ou livrotexto ou revista científica, bola-de-cristal, coleção indiscriminada de informação, censurada, democracia, campo-de-batalha, anarquia. Em suma, considerando os critérios de propósito na 
Figura 3, a razão para compilar a Wikipédia é reunir todo o conhecimento humano, para todos os públicos, sem restrição geográfica ou temática.

Quanto ao alcance, são poucas as limitações ao tipo de informação que pode ser abordado nos verbetes. Também não se limita o período de tempo ou os idiomas. As biografias de pessoas vivas são desaconselhadas, mas existem. Os conteúdos publicados não podem ferir direitos de cópia (copyright).

A limitação essencial de alcance é haver "interesse enciclopédico", o que também implica evitar conhecimento original (resultados primários de pesquisa), propaganda, difamação, censura etc. Na prática, há crítica reconhecida (CRITICISM, 2017) à cobertura excessiva de temas considerados populares. Defensores de temas "alternativos", tais como tratamentos de saúde ditos "holísticos", criticam as diretrizes da Wikipédia que os excluem. Tópicos "alternativos" foram refutados por Jimmy Wales sob argumento de que a Wikipédia cobre apenas temas publicados em periódicos científicos respeitados.

Em termos de línguas e tamanhos, a lista de wikipédias (LIST, 2017) informa que há atualmente 295 wikipédias, treze delas com mais de um milhão de verbetes. No total, são mais de 44 milhões de verbetes. A ausência dos custos e limites físicos associados à publicação em papel certamente favoreceu essa expansão rápida da Wikipédia.

Em comparação com outras enciclopédias (SIZE, 2017), a Wikipédia anglófona, com 5.382.445 verbetes, é a maior do mundo e tem tamanho médio de verbete de 605 palavras. É seguida pela Baike.com, um wiki chinês, com quase quatro milhões de verbetes de tamanho médio de 1.097 palavras. Em comparação, as versões impressa de 2013 e online da Britannica têm, respectivamente, 40.000 e 120.000 verbetes, com tamanho médio de 650 e 370 caracteres.

Quanto ao arranjo, a organização da informação e a recuperação de conteúdo são facilitadas pela disposição dos verbetes em hipertexto, com cada verbete em uma página dedicada e toda a Wikipédia exclusivamente na Web. Isso favorece encontrar os verbetes usando buscadores ou navegando através dos verbetes e outras páginas da Wikipédia. Não há propriamente uma divisão por assunto, mas há recursos de agregação e classificação, entre eles:

a) Portais, como o Library and Information Science, dedicado à ciência da informação e biblioteconomia, visível na Figura 4, item (7).

b) Listas diversas em páginas próprias.

c) Templates (quadros ou modelos - https://en.wikipedia.org/wiki/Help:Template), que podem ser usados para diversas finalidades, inclusive para organização de assuntos. Nesses casos, são agrupamentos de links dispostos na horizontal ou vertical com o fim de facilitar a navegação no grupo de links.

d) Categorias (https://en.wikipedia.org/wiki/Help:Category) que facilitam a navegação do leitor através de assuntos, organizadas em estrutura de árvore. Os links para categorias aparecem usualmente na parte inferior de um verbete, como se vê na Figura 4, item (9). 
Figura 4 - Excerto de página da Wikipédia com partes (5 a 9) em destaque

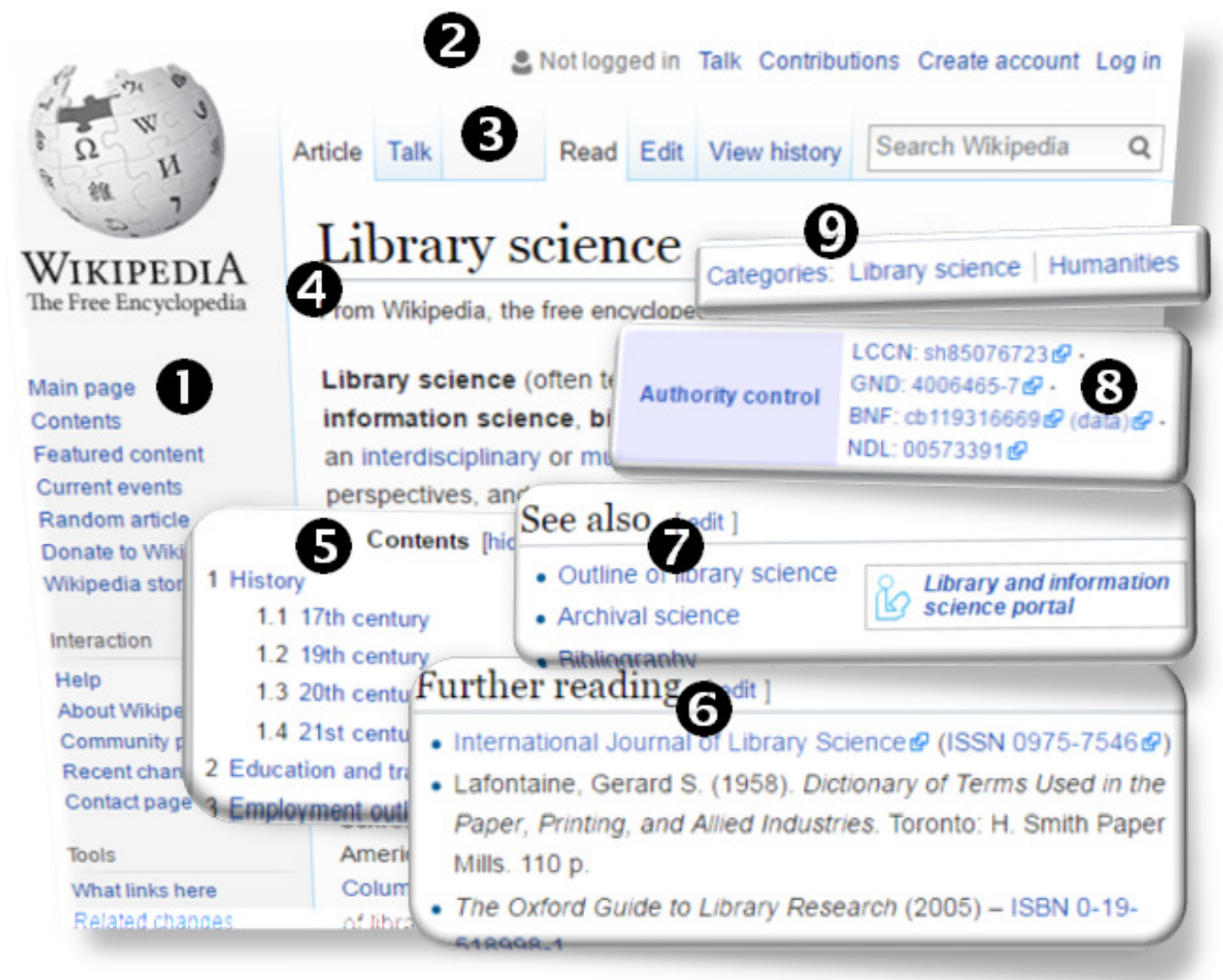

Fonte: Wikipédia, https://en.wikipedia.org/wiki/Library_science (acesso em 13/04/2017).

Quanto à informação dada, há flexibilidade na composição do conteúdo, que inclui elementos multimídia, bem como na organização de cada verbete, embora haja elementos de uso geral. A Figura 4 contém um trecho de verbete com seções em destaque. O menu geral à esquerda, item (1), e o menu de usuário ao alto, item (2), são partes fixas, presentes em qualquer verbete.

Quem acessa anonimamente, como nesse item (2), vê links para mensagens e contribuições de usuário associadas ao endereço IP (internet protocol) desde onde acessa. Quem entra no sistema com seu nome de usuário e senha vê opções associadas à sua conta: página de usuário, listas de contribuições e verbetes cuja edição acompanha etc. Esse "acompanhamento" é um registro que facilita ao wikipedista verificar as edições que vão sendo feitas aos verbetes acompanhados e, eventualmente, desfazer edições, voltando ao estado anterior.

O conteúdo do verbete começa com uma série de abas - item (3) na Figura 4. A aba principal (Article, duplicada na aba Read) permite ler o verbete. É possível, também, discutir questões sobre o conteúdo (aba Talk), editar (aba Edit) e ver o histórico completo de atualizações (aba View history).

O título do verbete, item (4) na Figura 4, é sucedido por um texto sintético, que tipicamente introduz o verbete em um ou poucos parágrafos. Logo a seguir vem um sumário (Contents), item (5), criado automaticamente pelo software de edição a partir dos títulos das seções do verbete. Após esse sumário vêm as seções específicas de conteúdo do verbete.

Na parte inferior da página, após as seções de conteúdo do verbete, é comum haver seções que direcionam o leitor a outros materiais, como "Leitura adicional" (Further reading), item (6) na Figura 4 e links externos (External links, não destacados na figura). Há listas de notas numeradas e de referências usadas no texto, não representadas na Figura 4 . O rodapé da 
página indica a data e hora da última modificação do verbete, bem como mais links genéricos sobre termos de uso, licença e direito de cópia (copyright), política de privacidade etc.

Quanto ao acesso, o principal meio é a busca online, seja na janela de busca junto às abas no topo de qualquer página da Wikipédia - item (3) na Figura 4, seja por meio de um buscador como o Google. Outra forma de acesso essencial é a navegação em hipertexto, por meio dos links para verbetes da Wikipédia ao longo do texto de qualquer verbete, ou em seções remissivas "Ver também" (See also), item (7), ou links em páginas agregadoras como portais, como no exemplo também no item (7), ou categorias, item (9) na Figura 4.

Páginas de desambiguação são recursos facilitadores de acesso essenciais na Wikipédia. Servem para auxiliar na escolha entre diversos verbetes associáveis a um único termo, como no exemplo da página https://en.wikipedia.org/wiki/Library (disambiguation), que aponta para mais de uma dezena de verbetes com distintas acepções e termos relacionados a library (biblioteca). Também há controle de autoridade, item (8) na Figura 4, com códigos e links para registros catalográficos.

Sumários e índices, fundamentais em enciclopédias em papel, encontram-se entre as características de acesso que Silberger (1990) recomenda avaliar. Porém, fazem pouco sentido numa enciclopédia online em hipertexto, inexistente à época da publicação do roteiro avaliativo.

Também faz pouco sentido avaliar a Wikipédia quanto à atualização, que é permanente. Cada verbete tem, no rodapé, a indicação de quando foi atualizada pela última vez. A atualização de cada verbete depende da iniciativa individual de contribuidores anônimos ou inscritos no sistema. Cada atualização de verbete é percebida por robôs e notificada aos editores interessados - embora não haja garantia de que alguém verificará esse novo conteúdo, como se discute adiante neste artigo.

Quanto ao equivalente automatizado, também não se aplica. O roteiro de Silberger (1990) é anterior à Wikipédia, num tempo em que editoras comerciais tratavam de criar conteúdo online considerado "equivalente automatizado" de suas enciclopédias em papel.

Quanto a características especiais, Silberger (1990) recomenda observar se a enciclopédia traz dicionário e atlas em volume separado. Esse papel cabe, na Wikipédia, aos "projetos irmãos", mantidos pela mesma hospedeira (Wikimedia Foundation) e listados na página principal (https://en.wikipedia.org/wiki/Main Page), entre eles o dicionário e tesauro multimídia Wiktionary (https://en.wiktionary.org), o repositório wiki multimídia gratuito Commons (https://commons.wikimedia.org), a coleção wiki de milhares de livros-texto e manuais Wikibooks (https://en.wikibooks.org), a lista (directory) de espécies biológicas com navegação taxonômica Wikispecies (https://species.wikimedia.org), o guia de viagem Wikivoyage (https://en.wikivoyage.org), a coleção voltada à aprendizagem do nível préescolar ao universitário Wikiversity (https://en.wikiversity.org) e o pacote de software gratuito MediaWiki (https://mediawiki.org), construído originalmente para a Wikipédia mas presente nos sítios web dos projetos irmãos e disponível para uso geral.

Outras características especiais notáveis são a página principal, as anotações editoriais nos verbetes, o help desk e a seção de referência (reference desk). A página principal lista e renova diariamente sua coleção de destaques, selecionados em processos bastante concorridos. Inclui um verbete (featured article) e uma imagem (featured picture) selecionados, coletâneas de notícias recentes, fatos notáveis no formato "Você sabia...?" ("Did you know...?") e fatos históricos ocorridos no dia e mês atuais ("On this day...").

As anotações editoriais nos verbetes são características distintivas da Wikipédia em relação a enciclopédias em papel. Apontam limitações e chamam a atenção do leitor e potenciais editores. Há anotações exibidas como tags (rótulos, etiquetas) sobrescritas no texto,

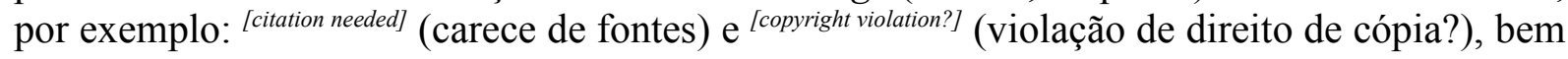


como na forma de quadro no alto da página ou em seção específica do verbete, com anotação mais extensa.

Anotações relacionadas a fontes e verificação de verbetes são descritas na página https://en.wikipedia.org/wiki/Wikipedia:Template messages/Sources of articles. A gama completa de anotações disponíveis tem apontadores a partir da página https://en.wikipedia.org/wiki/Wikipedia:Template messages.

A seção de referência (https://en.wikipedia.org/wiki/Wikipedia:Reference desk) é um serviço análogo, porém não idêntico, aos setores de referência em bibliotecas, pois os "bibliotecários de referência" são leigos voluntários. A help desk é uma página de ajuda sobre como usar ou editar a wikipédia anglófona (https://en.wikipedia.org/wiki/Wikipedia:Help desk). Também é, como quase tudo na Wikipédia, um serviço voluntário.

Isso conclui a avaliação da Wikipédia segundo o roteiro de Silberger (1990). Esse roteiro assume, implicitamente, o modelo de negócio vigente na época para enciclopédias baseado na reputação das editoras, que havia suplantado o modelo de negócio original das primeiras enciclopédias, baseado na reputação dos autores, pioneiros como Diderot e d'Alembert. Vale observar que dicionários brasileiros ainda seguem princípio semelhante, com nomes como Aurélio e Houaiss.

O avanço da Wikipédia sustenta-se em um modelo de negócio colaborativo baseado, conforme Gonçalves e Lima (2014), na autoridade do argumento, em detrimento do argumento de autoridade. Depende de autores e avaliadores de conteúdo voluntários. Dessa forma, além dos critérios de Silberger (1990), é preciso examinar também o processo de controle da qualidade do conteúdo a partir de princípios editoriais da Wikipédia.

Qualquer pessoa com acesso à internet pode, sob identidade real ou não, inclusive anonimamente, inserir ou alterar conteúdos de verbetes, exceto em poucos casos muito sensíveis a vandalismo ou outra perturbação (ABOUT, 2017). A avaliação para aceitar ou não esses novos conteúdos baseia-se em princípios amplos conhecidos como "cinco pilares". São eles (FIVE, 2017):

a) Caráter enciclopédico: Os verbetes devem ter "interesse enciclopédico", em contraste com conteúdo promocional, panfletário, jornalístico ou sem relevância e notoriedade.

b) Ponto de vista neutro: Busca-se representar os diversos pontos de vista eventualmente associados a um verbete com base em fontes fiáveis, verificáveis, num tom imparcial, evitando-se opiniões, interpretações (subjetivas), propaganda e advocacia.

c) Conteúdo livre: Há liberdade para usar, editar e distribuir desde que se respeite o direito de cópia, em contraste com o uso de conteúdo protegido ou incompatível com os requisitos legais de reuso na Wikipédia.

d) Respeito e civilidade: A convivência entre wikipedistas não admite insultos, ataques pessoais ou falta de etiqueta.

e) Flexibilidade das regras: há políticas e diretrizes, mas nenhuma é definitiva; admitemse exceções.

Esses princípios balizam a avaliação de conteúdos e servem como argumento, frequentemente, nas divergências sobre o aceite ou não de novas inserções. Cada versão da Wikipédia conta com um manual de estilo, com diretrizes para a composição de títulos, capitalização, itálicos, abreviações, pontuação, datas, uso de variantes de uma mesma língua etc. Em inglês, o manual de estilo está em https://en.wikipedia.org/wiki/Wikipedia:Manual of Style.

Os pilares, o manual de estilo e outras diretrizes são levados em conta na avaliação de novos conteúdos pelos editores da Wikipédia que são, em princípio, quaisquer usuários, incluindo os não-registrados e outras modalidades de usuário com mais ou menos privilégios, conforme descrito em https://en.wikipedia.org/wiki/Wikipedia:User_access_levels. A 
Wikipédia anglófona tem (ABOUT, 2017) mais de 30 milhões de usuários registrados, dos quais mais de 130 mil são "ativos" (editaram nos últimos 30 dias) e mais de 1200 são administradores.

O processo de tomada de decisão editorial é uma sequência de intervenções, todas registradas na aba "View history" - item (3) na Figura 4, que pode incluir remoções, emendas, reversões de edições feitas e mesmo a rejeição completa de um artigo por qualquer editor. Essa sequência de intervenções é que pode tornar-se, ocasionalmente, uma "guerra de edições" que requer a intervenção de editores cada vez mais graduados (até o caso-limite, que é a intervenção de Jimmy Wales).

Há diversas modalidades de supervisão e controle dos verbetes da Wikipédia (EDITORIAL, 2017), mas suas páginas não são claras quanto ao funcionamento preciso do processo editorial. Só vim a esclarecer este ponto após postar uma pergunta na seção de referência da Wikipédia, em https://en.wikipedia.org/wiki/Wikipedia:Reference desk/Miscellaneous\#What .28exactly.29 is the workflow for a new Wikipedia article.3F .28Wikipedia doesn. $27 \mathrm{t}$ tell.2C please no fairy tales....29. Cabe observar que o serviço de referência não existe na Wikipédia lusófona.

Segundo os "bibliotecários de referência" wikipedistas que responderam minha questão, o processo de decisão é caótico e acontece em bases voluntárias. Um novo verbete é aceito a priori, a menos que algum editor o marque para exclusão. Novos verbetes podem ser criados diretamente na Wikipédia ou em espaços próprios para iniciação, antes de implantar como verbete. Cada verbete pode ser vigiado ou "patrulhado" (patrolled) por quem quiser inscrever-se para, assim, intervir nas alterações. Há editores especializados em pequenos ajustes e correções, bem como robôs (software) que rastreiam vandalismo, páginas não vigiadas etc. para expor aos interessados em revisar.

A estrutura de poder que baliza as decisões editoriais na Wikipédia é a mesma que rege outros projetos da fundação Wikimedia. Tem elementos de (WIKIMEDIA POWER STRUCTURE, 2017) anarquia (pois qualquer um edita, inclusive anonimamente), despotismo (pois Jimmy Wales tem a última palavra, se quiser), democracia (pois o voto substitui o consenso, quando necessário), república (dados os poderes específicos de administradores, representantes de grupos de usuários), meritocracia (embora esse termo seja usado com reservas), plutocracia (dado que alguém pode estimular com financiamento a edição em certas áreas), tecnocracia (pois há técnicos com poder para escrever e alterar software) e burocracia (dada a complexa coleção de diretrizes).

Além do crivo para publicação, a avaliação de verbetes se destaca entre as iniciativas para detectar e promover a qualidade do conteúdo. Qualquer usuário pode avaliar um verbete (DALIP et al., 2017) nas seguintes categorias, em ordem decrescente: em destaque (FA ou featured article), completo (AC ou A-Class), bom (GA ou good article), útil (BC ou B-Class), inicial (ST ou Start-Class) e rascunho (SB ou Stub-Class). Há um guia para melhorar verbetes e submetê-los a revisão por pares visando a nominá-los para subir de categoria (https://en.wikipedia.org/wiki/Wikipedia:Peer review).

O controle da qualidade do conteúdo, recém-descrito, foi experimentado pelo autor deste artigo em sua primeira experiência como wikipedista, criador do verbete "Instituto Stela" na Wikipédia lusófona (https://pt.wikipedia.org/wiki/Instituto_Stela), cujo histórico completo de edições está em https://pt.wikipedia.org/w/index.php? title=Instituto Stela\&action=history. Foi minha única criação de verbete até o momento, embora tenha feito alterações em diversos verbetes. Postulo que a experiência é ilustrativa da aplicação dos princípios editoriais da Wikipédia.

A motivação para a criação foi constatar que havia diversos verbetes sobre instituições não-estatais de pesquisa brasileiras. O Instituto Stela, onde eu então atuava como pesquisador, 
parecia merecer menção nesse contexto, como cocriador da Plataforma Lattes e outras iniciativas que compõem a infraestrutura informacional brasileira na área de ciência, tecnologia e inovação.

Como se pode ver no histórico de edições do verbete, a primeira versão foi gravada às 12:30 de 9 de abril de 2010. Era uma versão sumária, postada com a intenção de complementar mais tarde. Porém, poucas horas depois, recebi uma mensagem prevendo uma "eliminação semirrápida" (em quatro dias) por "Notoriedade não relevada nem baseada em fontes não primárias. Possível uso da wiki para divulgação". Essas razões constam na terceira versão do verbete, em $\quad$ https://pt.wikipedia.org/w/index.php? title=Instituto Stela\&oldid=19629014.

Criei também o verbete "Editora Instituto Stela", igualmente marcado para "eliminação semirrápida" pelas mesmas razões, que nesse caso me levaram a não prosseguir editando. Persisti editando o verbete "Instituto Stela", por entender que havia interesse enciclopédico. O e-mail trocado com o editor que notificou a potencial eliminação pode ser visto na página de discussão do usuário vmkern, em https://pt.wikipedia.org/wiki/Usu \%C3\%A1rio(a) Discuss\%C3\%A3o:Vmkern.

Consta nessa página o pedido de tutoria que fiz, buscando entender o processo de avaliação e as razões da eliminação proposta. Apresentei três pontos de dúvida, que foram esclarecidos. O primeiro era terminológico: inicialmente não entendi o que seria "notoriedade não relevada", mas expressava o duvidoso interesse enciclopédico do novo verbete desde o ponto de vista do avaliador. O segundo tratava da falta de fontes citadas no verbete original. No terceiro ponto, minha dúvida era sobre o conflito de interesses representado por minha condição de contratado da instituição objeto do verbete. Segundo o avaliador, o conflito de interesses não impede a autoria, desde que se adote um "tom imparcial", ou seja, o ponto de vista neutro, que é um dos cinco pilares da Wikipédia (FIVE, 2017).

Ainda na página de discussão do usuário, meu tutor me alerta para o caráter "radicalmente diferente do da Wikipédia anglófona" para decidir eliminações na Wikipédia lusófona. "[A]s eliminações polêmicas acabam em simples votações", o que é uma das grandes vulnerabilidades da Wikipédia: frequentemente assumir a opinião da maioria como critério de verdade. Aparentemente, segundo meu tutor, a Wikipédia lusófona investe menos esforço no debate racional e resolve rapidamente as polêmicas, votando.

Entendidas as razões para a eliminação proposta, fiz as mudanças necessárias em tempo hábil e o verbete permaneceu. Nessa experiência, constatei que o processo de avaliação é explícito e transparente, dado que fica registrado no histórico de edições do verbete. Além disso, o teor das críticas me pareceu suficientemente objetivo, o que permitiu entendê-las e corrigir o texto.

\section{Discussão}

O termo "avaliação", no roteiro de Silberger (1990), tem o sentido de análise para considerar a aquisição e orientar o uso, não o de chegar a um escore redutor, comparável a escores de outras enciclopédias. Nesse sentido, os resultados na seção anterior dizem respeito à perspectiva de se adotar a Wikipédia como obra de referência e como usá-la.

O roteiro é anterior à Wikipédia e assume, tacitamente, que o modelo de negócio é único: são enciclopédias em papel, com credibilidade associada à reputação da empresa publicadora, que contrata autores enciclopedistas profissionais. Os critérios de avaliação tratam da diversidade e aprofundamento do conteúdo, mas não do controle da qualidade desse conteúdo, nem do fenômeno social da produção colaborativa voluntária que está na essência da emergência, crescimento, manutenção e potencial decadência da Wikipédia. É preciso discutir esses aspectos inexistentes na avaliação das enciclopédias em papel. 
Comecemos pelos aspectos comuns entre a Wikipédia e as outras enciclopédias, nos quais é tão ou mais efetiva que as demais enciclopédias quanto ao propósito, arranjo, acesso e informação dada. Há que considerar, entretanto, que a informação dada varia muito conforme o verbete e o arranjo e acesso não apresentam todas as características das enciclopédias em papel, nem é necessário, pois muitas dessas características - por exemplo, sumário e arranjo alfabético - são obsoletas numa obra em hipertexto em que a busca online é o recurso de acesso por excelência.

O alcance é significativamente mais vasto quanto à cobertura de idiomas e à gama de assuntos, ainda que isso seja evidente quanto a temas "populares" e discutível quanto a temas "clássicos". Além disso, enciclopédias em papel tendem a seguir diretrizes quanto ao alcance, enquanto a Wikipédia pode variar muito em profundidade e extensão conforme o verbete, já que todo trabalho é voluntário.

As características especiais de enciclopédias citadas por Silberger (1990) são dicionário e atlas em volume separado. A Wikipédia extrapola em muito as características especiais usuais em seus projetos-irmãos, que incluem dicionário, repositório multimídia, diretório de espécies biológicas e guia de viagem, todos em wiki. As seções de referência e helpdesk favorecem o leitor de maneira que uma enciclopédia em papel não poderia.

Em suma, a Wikipédia é comparável ou claramente superior às demais enciclopédias no que tange aos quesitos de avaliação de Silberger (1990). Resta a questão da qualidade e do controle da qualidade do conteúdo da Wikipédia, que difere qualitativamente do praticado pelas enciclopédias tradicionais. O processo editorial é colaborativo, caótico, transparente e baseado em diretrizes de qualidade, mas ocasionalmente falha.

Há erros não-intencionais, devidos à incapacidade individual ou coletiva dos editores. Quanto aos intencionais, há vandalismo e formas variadas de promoção ou sectarismo, embora desconheçam-se estudos sistemáticos sobre esses fenômenos.

Um vandalismo famoso permaneceu por seis meses sem correção na Wikipédia anglófona, em 2005, até ser detectado por um amigo do retratado, o jornalista John Seigenthaler (WIKIPEDIA SEIGENTHALER BIOGRAPHY INCIDENT, 2017). O jornalista foi falsamente declarado suspeito dos assassinatos do advogado-geral norte-americano Robert Kennedy, de quem fora assessor e amigo, e de seu irmão presidente, John. A correção foi rápida, o vândalo anônimo, identificado, mas Seigenthaler mostrou-se ofendido. É um exemplo típico de vandalismo sem correção imediata na Wikipédia: raro, mas o problema é a intensidade do dano, não a frequência.

No campo da propaganda e sectarismo, há também histórias bem conhecidas. Giles (2005) relatou a luta do pesquisador do clima William Connoley contra edições por negacionistas do aquecimento global, por dois anos. Como regra, verbetes pseudocientíficos não devem constar na Wikipédia. A versão anglófona registra a supressão desses temas em https://en.wikipedia.org/wiki/Wikipedia talk:WikiProject Skepticism/Pseudoscience/Archive 2.

A Wikipédia lusófona não observa o mesmo rigor. O verbete "Conscienciologia", por exemplo (https://pt.wikipedia.org/wiki/Conscienciologia), chega a assinalar o caráter pseudocientífico, mas sem destacá-lo, e apresenta o assunto de forma tão detalhada que um estudante desavisado pode tomá-lo por verdadeiro. Essa aceitação da pseudociência na Wikipédia lusófona pode ser consequência da preferência pelo voto em detrimento do debate racional embasado em fontes fiáveis como critério de decisão, conforme menciona a seção anterior. Se é assim, basta formar maioria na Wikipédia lusófona; não é preciso ter bons argumentos.

Uma crítica comum à Wikipédia é que falta autoridade da fonte. Passarelli (2008), no contexto da comunicação científica, argui que a autoridade das fontes é contestada quando não há revisão por pares. Nesse sentido, a Wikipédia não deveria ser vista como desprovida de 
autoridade, uma vez que as edições de verbetes estão sujeitas ao escrutínio de outros editores e a crítica é transparente - característica ainda rara entre as revistas científicas.

Ainda que a hierarquia de editores não atenda a critérios acadêmicos, o escrutínio é potencialmente rigoroso, conforme meu relato anedótico anterior. Encontrei nessa experiência a transparência e a objetividade que faltam em alguns processos avaliativos acadêmicos.

Minha experiência como autor wikipedista, embora pontual, é de que a avaliação de novos conteúdos na Wikipédia é uma revisão pública com características semelhantes à da revisão por pares acadêmica. De fato, Tennant et al. (2017) a incluem entre nove modelos potenciais futuros de revisão por pares, embora o revisor da Wikipédia possa autonomear-se editor da Wikipédia, diferentemente do revisor acadêmico, que precisa alcançar antes algum prestígio e o convite de um editor.

Quanto à qualidade típica dos verbetes, a revisão sistemática de Mesgari et al. (2015) parece confirmar uma tendência a aceitar a Wikipédia como fonte fiável, embora a franca maioria dos estudos refira-se à versão anglófona. Chesney (2012) comparou a percepção de pesquisadores sobre a credibilidade da Wikipédia, de seus autores e de artigos específicos. Os respondentes receberam um artigo, que podia ou não pertencer à sua especialidade. Os respondentes especialistas manifestaram haver maior credibilidade no conteúdo dos artigos do que os respondentes não-especialistas. Ou seja, peritos confiaram mais no conteúdo que nãoperitos, o que é um sinal favorável à Wikipédia.

Para o cofundador Sanger (2009), cada verbete evoluirá aleatoriamente em torno da melhor qualidade possível permitida pelos wikipedistas mais persistentes e agressivos que o seguem. Manter a qualidade requer trabalho árduo e constante, conforme a entrevista de Riehle (2006) com editoras líderes das wikipédias em inglês, alemão e japonês.

Quanto ao fenômeno social, a emergência da Wikipédia foi proporcionada pela assim chamada Web 2.0, em que a fronteira tradicional entre produtores e consumidores de informação e conhecimento foi borrada (AIBAR et al., 2015). A literatura científica registra estudos que recomendam aos docentes do ensino superior apropriar-se desse caráter de commons (bem comum) da Wikipédia e da derrubada dessa barreira produção-consumo.

Jennings (2008) já conclamava professores e bibliotecários a "remover o estigma" associado à Wikipédia e usá-la para ensinar competência em informação. Konieczny (2012) afirma que a Wikipédia era vista, até há poucos anos, como "um bárbaro invadindo a torre de marfim", mas que cresce, atualmente, o número de docentes que a reconhecem como uma ferramenta de ensino potencialmente efetiva. Para Okoli et al. (2014), a Wikipédia oportuniza educar estudantes a serem competentes em informação. A própria Wikipédia oferece recursos para quem quer contribuir com conteúdo ${ }^{4}$ e lista iniciativas universitárias e secundárias de edição como parte das atividades de aprendizagem e avaliação ${ }^{5}$.

Por fim, arrisco-me a responder à pergunta que motivou a pesquisa: $\mathrm{O}$ que sustenta a aceitação da Wikipédia em fóruns como revistas científicas de elite? Primeiramente, a necessidade eventual de recorrer a obras de referência para citar conceitos necessários. Isso já acontecia com outras fontes, como a Encyclopedia Britannica, como ilustrado na Figura 1.

Em segundo lugar, ao citar uma fonte de referência, o cientista precisa percebê-la como confiável. A considerar os estudos sobre a qualidade do conteúdo da Wikipédia (MESGARI et al., 2015), essa percepção de confiabilidade predomina sobre a desconfiança.

\section{Conclusão}

Esta pesquisa partiu da indagação sobre o que sustenta a aceitação da Wikipédia como fonte em fóruns de alto nível como os periódicos que estão na Web of Science. A resposta sucinta é:

4 https://en.wikipedia.org/wiki/Wikipedia:Contributing_to_Wikipedia

5 https://en.wikipedia.org/wiki/Wikipedia:School_and_university_projects 
cientistas percebem o conteúdo da Wikipédia como de alta qualidade e o citam quando eventualmente necessitam recorrer a um conceito enciclopédico.

Já existe uma quantidade considerável de estudos sobre a qualidade da Wikipédia, muitos deles sumariados numa revisão sistemática (MESGARI et al., 2015), predominantemente favoráveis. A grande maioria dos estudos refere-se à versão anglófona. Quanto às demais wikipédias, é difícil avaliar a qualidade, pois há poucos estudos.

A avaliação da Wikipédia pelo roteiro de Silberger (1990) permitiu constatar que não há desvantagem clara em relação a outras enciclopédias, em qualquer dos critérios analisados: propósito, alcance, arranjo, informação dada, acesso e características especiais. Pelo contrário, a disponibilidade gratuita online e o grande volume de informação fazem o alcance e as características especiais da Wikipédia claramente superiores ao que se encontra nas enciclopédias em papel. Dois critérios do roteiro de Silberger (1990) foram desprezados por obsolescência: atualização e equivalente automatizado.

O roteiro usado assume tacitamente o modelo de negócio das enciclopédias em papel: edição por profissionais contratados, expectativa de qualidade baseada na reputação da editora, venda da obra em papel. Por isso, em adição aos critérios de Silberger, um aspecto adicional foi avaliado: o controle da qualidade do conteúdo, pouco conhecido por quem critica a Wikipédia de forma categórica e acrítica.

Resulta que a avaliação de novos conteúdos na Wikipédia é decidida num processo assemelhado à revisão por pares acadêmica, como ilustra um relato da experiência do autor como wikipedista. As principais diferenças em relação às formas usuais de revisão por pares acadêmica são: os avaliadores são voluntários sem formação acadêmica informada, a revisão é aberta e o processo editorial é transparente, pois todas as interações, incluindo exclusões de conteúdo, ficam visíveis.

A Wikipédia não é apenas uma enciclopédia online, mas também um bem comum, um commons. Sua qualidade e manutenção dependem do excedente cognitivo, isto é, do tempo livre das pessoas escolarizadas (SHIRKY, 2010). É reconhecida entre as mais bem-sucedidas iniciativas colaborativas na Web, baseada na confiança entre milhões de contribuidores e leitores, sustentada por normas que promovem confiabilidade e objetividade (KRANICH; SCHEMENT, 2008).

A Ciência da Informação se postula ciência social. "Ocupar" a Wikipédia parece um passo natural para os pesquisadores da área. Silva (2017, p. 94) a chama de "velho sonho iluminista tornado possível através da 'galáxia internet"”. Logan et al. (2010, p.1) consideram editar a Wikipédia "uma excelente maneira de cumprir as responsabilidades de participação pública e compartilhar conhecimentos" por parte dos cientistas e propõem dez regras simples para editar a Wikipédia.

Nesse sentido, a iniciativa de trazer a Wikipédia para dentro da sala de aula universitária é incentivada por diversos autores. Jemielniak e Aibar (2016, p. 1775) dizem que "se não começarmos a contribuir para a Wikipédia, o trem sairá sem nós" e Mahesh (2017) espera que a academia, sem demora, contribua para e colabore com a Wikipédia. Há iniciativas nesse sentido de entidades acadêmicas importantes, como o acordo de cessão de conteúdo da Oxford University Press (https://en.wikipedia.org/wiki/Wikipedia:OUP) para wikipedistas experientes usarem para contribuir para a Wikipédia.

Finalmente, é preciso reconhecer que a evidência de alta qualidade na Wikipédia anglófona é copiosa, mas faltam estudos sobre outras wikipédias. Na Wikipédia lusófona, em particular, o cumprimento das diretrizes editoriais na Wikipédia lusófona me parece precário e os erros de português, numerosos. Faltam estudos sistemáticos que verifiquem esses aspectos. 


\section{Agradecimentos}

O autor agradece as críticas dos wikipedistas avaliadores Stegop e Braswiki na ocasião de sua primeira experiência como editor da Wikipédia, relatada na seção Resultados. Também, à Dra. Luciana Martins Saraiva, por comentários críticos, e à doutoranda Paula Balbis, por comentários críticos e sugestão de fonte.

\section{Referências}

ABOUT. In: Wikipedia, the free encyclopedia. Flórida: Wikimedia Foundation, 19 mar. 2017. Disponível em: <https://en.wikipedia.org/wiki/Wikipedia:About $>$. Acesso em: 10 abr. 2017.

AIBAR, E.; LLADÓS-MASLLORENS, J.; MESEGUER-ARTOLA, A.; MINGUILLÓN, J.; LERGA, M. Wikipedia at university: What faculty think and do about it. The Electronic Library, v. 33, n. 4, p. 668-683, 2015.

ARAZY, O.; NOV, O.; PATTERSON, R.; YEO, L. Information quality in Wikipedia: The effects of group composition and task conflict. Journal of Management Information Systems, v. 27, n. 4, p. 71-98, 2011.

BRITANNICA, Encyclopaedia. Fatally flawed. Refuting the recent study on encyclopedic accuracy by the journal Nature. 2006.

CHESNEY, T. An empirical examination of Wikipedia's credibility. First Monday, v. 11, n. 11, 2006. Disponível em: $<$ http://dx.doi.org/10.5210/fm.v11i11.1413 $>$. Acesso em 11 jan 2017.

CRITICISM of Wikipedia. In: Wikipedia, the free encyclopedia. Flórida: Wikimedia Foundation, 23 mai. 2017.2 Disponível em:

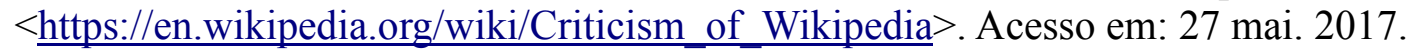

D'ANDREA, C. F. B. Enciclopédias na web 2.0: colaboração e moderação na Wikipédia e Britannica Online. Em Questão, v. 15, n. 1, p. 73-88, 2009.

DALIP, D. H.; GONÇALVES, M. A.; CRISTO, M.; CALADO, P. A general multiview framework for assessing the quality of collaboratively created content on web 2.0. Journal of the Association for Information Science and Technology, v. 68, n. 2, p. 286-308, 2017.

DEMO, P. Coisas velhas em coisas novas: novas "velhas tecnologias". Ciência da Informação, v. 39, n. 1, p. 108-121, 2010.

EDITORIAL oversight and control. In: Wikipedia, the free encyclopedia. Flórida: Wikimedia Foundation, 12 fev. 2017.2 Disponível em: $<$ https://en.wikipedia.org/wiki/Wikipedia:Editorial oversight and control>. Acesso em: 15 mai. 2017.

ENCYCLOPEDIA. In: Wikipedia, the free encyclopedia. Flórida: Wikimedia Foundation, 25 dez. 2016. Disponível em: <https://en.wikipedia.org/wiki/Encyclopedia $>$. Acesso em: $28 \mathrm{dez}$. 2016.

FIVE pillars. In: Wikipedia, the free encyclopedia. Flórida: Wikimedia Foundation, 31 mar.

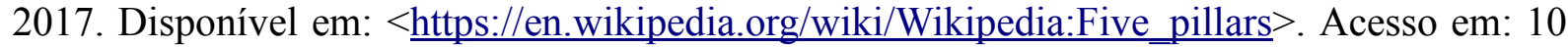
abr. 2017.

GILES, Jim. Internet encyclopaedias go head to head. Nature, v. 438, n. 7070, p. 900-901, 2005. 
GONÇALVES, M.; LIMA, C. V. M. Pretensões de validade da informação diante da autoridade do argumento na Wikipédia. Tendências da Pesquisa Brasileira em Ciência da Informação, v. 7, n. 2, 2014.

HJØRLAND, B. Evaluation of an information source illustrated by a case study: Effect of screening for breast cancer. Journal of the American Society for Information Science and Technology, v. 62, n. 10, p. 1892-1898, 2011.

JEMIELNIAK, D.; AIBAR, E. Bridging the gap between Wikipedia and academia. Journal of the Association for Information Science and Technology, v. 67, n. 7, p. 1773-1776, 2016.

JENNINGS, E. Using Wikipedia to teach information literacy. College \& Undergraduate Libraries, v. 15, n. 4, p. 432-437, 2008.

KONIECZNY, P. Wikis and Wikipedia as a teaching tool: Five years later. First Monday, 2012. Disponível em: $<$ http://dx.doi.org/10.5210/fm.v0i0.3583 $>$. Acesso em 11 jan 2017.

KRANICH, N.; SCHEMENT, J. R. Information commons. Annual Review of Information Science and Technology, v. 42, n. 1, p. 546-591, 2008.

LIST of Wikipedias. In: Wikipedia, the free encyclopedia. Flórida: Wikimedia Foundation, 4 abr. 2017, 7:30. Disponível em: <https://meta.wikimedia.org/wiki/List_of_Wikipedias $>$. Acesso em: 12 abr. 2017.

LOGAN, D. W.; SANDAL, M.; GARDNER, P. P.; MANSKE, M.; BATEMAN, A. Ten simple rules for editing Wikipedia. PLoS Computational Biology, v. 6, n. 9, p. e1000941, 2010.

MAHESH, G. Academia's recognition of Wikipedia. Letter to the editor. Journal of the Association for Information Science and Technology, vol. 68, n. 6, p. 1596, 2017.

MESGARI, M.; OKOLI, C.; MEHDI, M.; NIELSEN, F. Å.; LANAMÄKI, A. "The sum of all human knowledge": A systematic review of scholarly research on the content of Wikipedia. Journal of the Association for Information Science and Technology, v. 66, n. 2, p. 219245, 2015.

OKOLI, C.; MEHDI, M.; MESGARI, M.; NIELSEN, F. Å.; LANAMÄKI, A. Wikipedia in the eyes of its beholders: A systematic review of scholarly research on Wikipedia readers and readership. Journal of the Association for Information Science and Technology, v. 65, n. 12, p. 2381-2403, 2014.

OVERVIEW FAQ. In: Wikipedia, the free encyclopedia. Flórida: Wikimedia Foundation, 5 mar. 2017. Disponível em: <https://en.wikipedia.org/wiki/Wikipedia:FAQ/Overview>. Acesso em: 10 abr. 2017.

PASSARELLI, B. Do mundaneum à web semântica: discussão sobre a revolução nos conceitos de autor e autoridade das fontes de informação. DataGramaZero, v. 9, n. 5, p. 00, 2008.

RIBEIRO, A. L. R.; GOTTSCHALG-DUQUE, C. Wikipédia e enciclopédia britânica: Informação confiável? Revista Brasileira de Biblioteconomia e Documentação, v. 7, n. 2, p. 172-185, 2012.

RIEHLE, D. How and why wikipedia works: an interview with Angela Beesley, Elisabeth Bauer, and Kizu Naoko. In: Proceedings of the 2006 international symposium on Wikis. ACM, 2006. p. 3-8. 
SANGER, L. M. The fate of expertise after Wikipedia. Episteme, v. 6, n. 01, p. 52-73, 2009.

SHIRKY, C. Cognitive surplus: creativity and generosity in a connected age. New York: Penguin Books, 2010.

SHIRKY, C. Here comes everybody: The power of organizing without organizations. Penguin Books, 2008.

SILBERGER, K. K. Obras de referência: subsídios para uma avaliação criteriosa. Florianópolis: Ed. da UFSC, 1990.

SILVA, A. M. Que ciência da informação precisamos para enfrentar a complexidade? PontodeAcesso, v. 11, n. 1, p. 85-114, 2017.

SIZE comparisons. In: Wikipedia, the free encyclopedia. Flórida: Wikimedia Foundation, 5 fev. 2017. Disponível em: <https://en.wikipedia.org/wiki/Wikipedia:Size_comparisons $>$. Acesso em: 12 abr. 2017.

SOUSA, C. H. P.; MARQUES, F. P. J. A. Wikipedia, democracy and local elections in São Paulo: a study of the developing of articles edited during the election campaign in 2012 . Revista Eletrônica de Comunicação, Informação \& Inovação em Saúde, v. 9, n. 2, 2015.

STVILIA, B.; TWIDALE, M. B.; SMITH, L. C.; GASSER, L. Information quality work organization in Wikipedia. Journal of the Association for Information Science and Technology, v. 59, n. 6, p. 983-1001, 2008.

TENNANT, J. P. et al. A multi-disciplinary perspective on emergent and future innovations in peer review [version 1; referees: awaiting peer review]. F1000Research, v. 6, n. 1151, 2017.

TOMASZEWSKI, R.; MACDONALD, K. I. A study of citations to Wikipedia in scholarly publications. Science \& Technology Libraries, v. 35, n. 3, p. 246-261, 2016.

WHAT Wikipedia is not. In: Wikipedia, the free encyclopedia. Flórida: Wikimedia Foundation, $\quad 8 \quad$ abr. 2017.20 Disponível

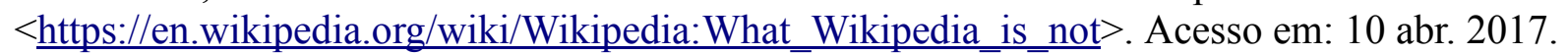

WIKIMEDIA POWER STRUCTURE. In: Wikimedia Meta-Wiki. Flórida: Wikimedia Foundation, 17 fev. $2017 . \quad$ Disponível $<$ https://meta.wikimedia.org/wiki/Wikimedia_power_structure> . Acesso em: 18 jul. 2017.

WIKIPEDIA. In: Wikipedia, the free encyclopedia. Flórida: Wikimedia Foundation, 8 abr.

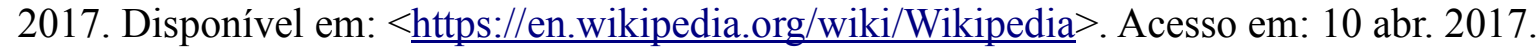

WIKIPEDIA SEIGENTHALER BIOGRAPHY INCIDENT. In: Wikipedia, the free encyclopedia. Flórida: Wikimedia Foundation, 25 abr. 2017. Disponível em: $<$ https://en.wikipedia.org/wiki/Wikipedia_Seigenthaler_biography incident $>$. Acesso em: 14 jun. 2017. 